Original article

\title{
Effect of electronic education based on health promotion model on physical activity in diabetic patients
}

\author{
Hamideh Lari ${ }^{\mathrm{a}}$, Rahim Tahmasebi ${ }^{\mathrm{b}, \mathrm{c}}$, Azita Noroozi ${ }^{\mathrm{a}, \mathrm{c}, *}$ \\ a Department of Health, Bushehr University of Medical Sciences, Bushehr, Iran \\ ${ }^{\mathrm{b}}$ Department of Biostatistics, Bushehr University of Medical Sciences, Bushehr, Iran \\ ${ }^{\mathrm{c}}$ The Persian Gulf Marine Biotechnology Research Center, Bushehr University of Medical Sciences, Bushehr, Iran
}

\section{A R T I C L E IN F O}

Article history:

Available online $\mathrm{xxx}$

\section{Keywords:}

Health promotion model

Physical activity

Type II diabetes

Multimedia training

\begin{abstract}
A B S T R A C T
Background: By high prevalence of inactivity, particularly in diabetic patients, the need to effective interventions to promote physical activity is essential. The aim of this study was to determine the effects of education based on health promotion model (HPM) through multimedia on the physical activity in diabetic patients.

Method: In this quasi-experimental study, 76 patients with type II diabetes were evaluated (40 patents in intervention group and 36 patients in control group). The intervention group members and a friend or a family member, that could be supportive in physical activity, received teaching CD based on health promotion model. Both group members at the beginning of the study, two weeks and three months after the training, completed questionnaires. After data collection, statistical analysis was conducted using independent T-test, chi-square test, and repeated measurement of ANOVA.

Results: Finding showed that self-efficacy $(P<0.001)$, health status $(p=0.032)$, benefits $(P<0.001)$ and friends support in physical activity $(\mathrm{P}<0.001)$ were perceived to be higher, and barrier of physical activity $(\mathrm{P}<0.001)$ was perceived to be lower in multimedia group compared to control group 3 months after training. There was a significant difference in average of metabolic equivalent of task (MET) between two groups after the intervention $(\mathrm{P}<0.001)$.

Conclusion: Planning of education based on the HPM and implementation through multimedia can change belief about physical activity and increase participation in physical activity.
\end{abstract}

(c) 2017 Diabetes India. Published by Elsevier Ltd. All rights reserved.

\section{Introduction}

Today, the rate of diabetes is significantly rising [1] as based on the World Health Organization report, the prevalence of diabetes in 2004 was around 194 million and this amount by the year 2025 will be 333 millions of people around the world and about half of the population will be in Asia and Oceania. According to the report of international diabetes federation, it is estimated that in 2014, the prevalence of diabetes in Iran was $8.43 \%$ [2].

Type 2 diabetes has high direct and indirect costs so has allocated $15 \%$ of the costs of health cares in the United States of America [3], and in many countries around the world, at least 10\% of the total cost of health care is spending for diabetics [4].

Environmental factors such as poor nutritional habits and especially lack of physical activity are effective in the development

\footnotetext{
* Corresponding author at: The Persian Gulf Marine Biotechnology Research Center, Bushehr University of Medical Sciences, Bushehr, Iran.

E-mail address: azitanoroozi@yahoo.com (A. Noroozi).
}

and progression of diabetes [5]. Physical activity through increasing the number of insulin receptors, increasing tissue level of glucose transporters and improving insulin sensitivity, causes long-term effects in increasing sensitivity to insulin $[6,7]$. Therefore, the World Health Organization has reported at least 30 min of daily average physical activity for at least 5 days a week or 25 min of vigorous physical activity for at least 3 times a week as a minimum physical activity to maintain good health and prevent diabetes [8]. In high-income countries, $26 \%$ of men and $35 \%$ of women and in low-income countries $12 \%$ of men and $24 \%$ of women are physically active, and studies have shown that the physical activity in diabetic patients is even less than the general population so in Great Britain $68 \%$ of the type II diabetes patients and $61 \%$ of patients with type II diabetes were classified as inactive [9]. International Diabetes Association believes that for preventing complications of diabetes, education in self-management behaviors, including physical activity can be successful up to $80 \%$, however, the impact of education depends on the appropriate use of behavioral change theories and appropriate educational techniques [10]. 
Since the base of diabetes control is on self-care and the main emphasis of health promotion model is also on self-regulation, so health promotion model for behavior change seems to be effective in this group of patients. This model includes three concepts including individual characteristics and experiences, behavioral specific cognition and affects and behavioral outcomes. The concept of individual characteristics and experiences include prior related behavior and personal factors and the concept of behavioral specific cognition and affects including constructs of perceived benefit and barrier, perceived self-efficacy, activity related affect, interpersonal influences (social support and norms) and situation influences. Professor Pender identified constructs of the model that were effective in more than $50 \%$ of studies including the prior related behavior, personal factors (perceived health status), perceived benefit and barrier, perceived self-efficacy and social support [11].

Nowadays researchers have used from technological development for provide interventions of health promotion. Multimedia easily communicates with users, due to its dynamic and attractive graphical effects and use of various visual and audio media. In this method, the learner will find the opportunity to practice more to reach the proficiency level. So, given the increasing use of computer as a communication tool, we can teach educational concepts in a charming and diverse atmosphere by the help of multimedia [12,13]. So considering the importance of physical activity in diabetes patients, this study aimed to determine the effect of education based on HPM using multimedia on physical activity in type II diabetic patients (Fig. 1).

\section{Materials and methods}

\subsection{Study design}

This quasi-experimental study has been carried out since October 2016 to February 2017 to assess the effect of electronic education on physical activity of diabetic patients with type II diabetes referring to two diabetes clinics in the city of Bushehr, a southwestern province in Iran.

Inclusion criteria for this study included being able to read and write, having no diabetic foot ulcers, willingness to participate in the study, having diabetes for 1 or more years; and exclusion criteria included functional inability to walk without a cane, inability to walk 1 mile with no rest, inability to continue participation in study for at least 3 months, and having cardiovascular disease.

The sample size was estimated based on similar study [14], 36 subjects for each group and with considering attrition rates (10\%) in three months fallow up, about 40 subjects were required for each groups. Two diabetes clinics were selected for sampling; reviewing 1775 records of patients in Haftom-e-Tir diabetes clinic, and 514 records in diabetes clinic of the Social Security Hospital taking into account the inclusion criteria, 145 patients in Haftom-

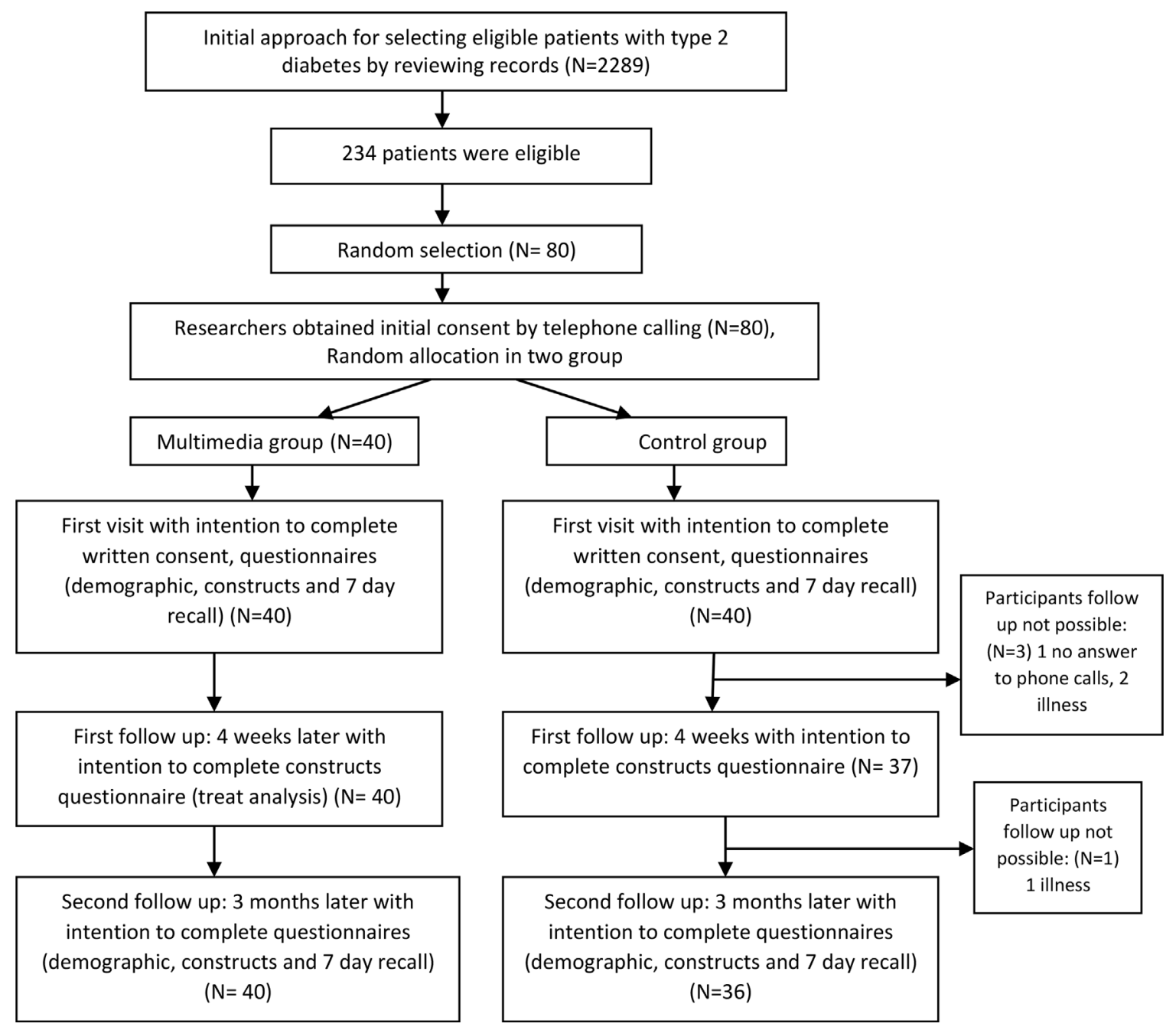

Fig. 1. Consort flow chart of participants. 
e-Tir clinic and 89 patients in Social Security Hospital were determined eligible, and 80 (out of 234) patients were selected using simple random sampling. After a phone call, people who would like to participate in the study were identified, and randomly divided in two groups of multimedia training and control group. From 40 participants in each group, 4 patients in control group were not willing to continue participation in the study and were excluded. Ultimately, 40 patients in multimedia group and 36 patients in the control group completed the study.

\subsection{Method and data collection}

At the beginning of the study, the patients in both groups attended at the clinic in a particular day determined by themselves, and completed the written consent form and then questionnaires including demographic questionnaire, HPM constructs, and 7-day physical activity recall questionnaire. Appointment interval was one hour per day so that the researchers have enough time to complete the physical activity questionnaire through interviews and to monitor the questionnaires completion.

Multimedia group members received educational CD based on HPM after completing the questionnaires. The following topics were in this educational CD:

Tips about the benefits of physical activity to control blood sugar and mental and physical effects of physical activity (perceived benefits);

Tips about the problems of doing physical activity, including problems related to physical activity in times of hyperglycemia and coping strategies and trainings to reduce muscle cramps rising of physical activity (perceived barriers);

Trainings based on step by step change of physical activity and increase it gradually over a period of 3 months and modify belief based on the usefulness of heart rate increase rising from physical activity (perceived self-efficacy).

These tips have been offered to patients as educational slides with audio recording and mobility of plates. Also, educational CD showed 8 strength move and 10 flexibility move suitable for diabetic patients.

A week after the package delivery, they dialed the person number and ensured that the educational CD has been opened by asking questions about its content.

In order to social support of friends, family members or significant people, the patients were asked to introduce the active family member or friends who can accompany them in performing physical activity. The special educational $C D$ for these members have been also designed and provided which in addition to the benefits, barriers and self-efficacy had also some advices about care, acceptance, trust and accompany with the patient (perceived support).

The educational CD was auto run and was displayed by click on any field. In addition to the $\mathrm{CD}$, multimedia group members, since receiving the training package to 3 months later, received weekly 2 messages via SMS to recall the tips.

Participants in both groups, 4 weeks after the completion of the first phase questionnaires, completed the questionnaires related to constructs of HPM, and 3 months after the second stage of data collection completed questionnaires related to constructs of HPM and questionnaire of 7-day recall of physical activity.

The participants of control group also after giving written consent, completed the questionnaires related to demographic factors, constructs of HPM and 7 day recall of physical activity at baseline of the study and 4 weeks later completed questionnaire related to constructs of HPM and three months later completed questionnaires related to constructs of HPM and 7 day recall of physical activity. The participants of control group received routine education of clinic and didn't receive training materials until the end of study.

\subsection{Instruments and measures}

Data collection tool in this study was a questionnaire consisted of three parts. The first part of the questionnaire contained information about the individual characteristics and experiences demographic factors) such as age, gender, education, household income, Body Mass Index (BMI), type of medication, prior related behaviors, and perceived health status.

Perceived health status was determined by 12 -item short form health survey examining the physical and mental health. Cronbach's alpha for this instrument in physical health aspect was 0.73 and mental health aspect was 0.72 [15], and in this study, Cronbach's alpha coefficient was obtained 0.79 for the entire tools.

The second part of the questionnaire contained questions related to constructs of HPM.

Perceived benefits: Sechrist and colleagues designed this instrument for determination of agreement or disagreement with physical activity benefits by 28 questions with 4-point Likert scale. Cronbach's alpha coefficient of this instrument was reported 0.89 [16]; in this study, Cronbach's alpha coefficient was obtained 0.93.

Perceived barriers: individuals' perceptions of barriers to physical activity were examined by 14 questions with 4-point Likert scale. Cronbach's alpha coefficient of this scale was reported 0.77 [16]; in this study, it was obtained 0.74 .

Perceived social support: People's perception of family and friends support in physical activity was measured with 15 and 5 questions respectively, with 5-point Likert scale. Cronbach's alpha coefficients were reported 0.9 and 0.86 for family and friends support, respectively [17]; in this study, it was obtained 0.92 for family support and 0.83 for the friend support.

Self-efficacy: confidence of people to do regular physical activity in different conditions was evaluated by Questionnaire of Norouzi et al. This questionnaire has 18 questions and it is answered by a percentage scale (0-100\%). Cronbach's alpha coefficient of the scale was reported 0.92 [18]; in this study, it was obtained 0.92 .

The third part of questionnaire measured the physical activity with a 7-day physical activity recall questionnaire. The questionnaire was completed by a semi-structured interview. In the interview, subjects were asked to remember the activities done in the last seven days, to determine the duration (in min), intensity (based on the changes occurred in heart rate compared to walking and running), and type of each activity (daily activities or leisure activities). Then, using the instructions given in these tools, the amount of MET was calculated in the last week. The reliability of these tools was studied in several investigations by an intra-class coefficient; it had a range between 0.34 and 0.99 . This questionnaire has been identified as a useful tool to assess the amount of physical activity [19]. In this study, intra-class coefficient was obtained 0.78 .

Height and weight of individuals were measured to determine MET and Body Mass Index. The data were analyzed by the statistical package for social sciences software (SPSS) version 22.0. Descriptive statistics, Chi-square test, independent $t$-test, and repeated measurement ANOVA were used for data analysis.

\subsection{Ethical consideration}

The study protocol followed the principals of the "Declaration of Helsinki". The participants were told that they could withdraw from the study at any time and that all information would be kept secret and anonymous. The required permissions for research were obtained from the vice chancellor of Bushehr University of Medical 
Sciences with ethics number IR.BPUMS.REC.1395.56. Written and informed consents were obtained from all the participating in the study.

\section{Results}

A total of 76 diabetic patients $(\mathrm{N}=40$ in multimedia group and $\mathrm{N}=36$ in control group) completed study. There were no significant differences between multimedia and control groups about individual characteristics and experience (demographic factors). For instance, the average age of participants in multimedia group was $47.35 \pm 8.47$, and the average age in control group was $49.13 \pm 9.07$ ( $\mathrm{p}=0.497)$. The mean \pm SD of BMI in multimedia and control group were $28.05 \pm 5.76$ and $26.92 \pm 3.93$ respectively $(\mathrm{p}=0.115)$, and duration of diabetes in two groups were $7.55 \pm 5.78$ in multimedia group and $8.77 \pm 5.73$ in control group $(\mathrm{p}=0.999)$. Other demographic characteristics were shown in Table 1.

Also, the participants in the SMS and control groups were similar in their health beliefs related to physical activity before education, but the difference between two groups was statistically significant after training in several constructs (Table 2).

Comparison of pre and post-test results (immediate and 3 months later) in multimedia group by repeated measurement ANOVA found that changes occurred in the perceived health status, perceived self-efficacy, perceived barrier, perceived benefit, friend and family support. The results demonstrated an increase in perceived health status, self-efficacy, perceived benefit, friend and family support as well as decrease in perceived barrier $(\mathrm{p}<0.001)$.

However, in the control group, the results showed that there were no significant changes between the pre- and post-test scores for the all of constructs.

Comparison of two groups during the time showed that no difference noted in the scores of family support between two groups $(p=0.052)$, but health status, self-efficacy, benefit, and friend support were perceived to be higher and barrier was perceived to be lower at the multimedia group compared to control group (Table 2).

Pre and post-test mean difference of MET between two groups was statistically significant $(\mathrm{p}<0.001)$. The mean \pm SD of MET in multimedia and control groups during time were shown in Table 3.

\section{Discuss}

In this study, multimedia training improved perceived health status, self-efficacy for physical activity, perceived benefits of physical activity, friends support for physical activity and also reducing perception of barriers of physical activity. In addition, there were statistically significant difference between the two groups during times in terms of perceived health status, self- efficacy, benefits, perceived barriers and the support of friends in doing physical activity so that patients in multimedia group had more understanding of the efficacy, benefits, health statue and friends support and less perceived barriers to doing physical activity.

Self-efficacy in multiple studies has been expressed as determinants of physical activity behavior [20-22], therefore its promotion will be an important factor in promoting physical activity behavior. In this study, learning through multimedia by providing positive feedback and encouraging people to daily record of physical activity promotion had enhanced the perceived self-efficacy in physical activity. Consistent to the findings of recent study results in a study based on social-cognitive theory found that self-efficacy in diabetic women has been effective in increasing physical activity [23].

In this study, multimedia could significantly reduce people's perception of barriers to physical activity that this finding was approved by several studies that provided individual [24] or group training [25]. In addition, training through multimedia based on social-cognitive theory also had been able to change diabetic women's perception of the barriers to physical activity [23], therefore dynamism and attractiveness education by audio-visual media (multimedia) can reduce people's perception of barriers to physical activity and this training method seems a good way to reduce perceived barriers.

In many studies have identified that social support including family or friends, both directly and indirectly through promoting knowledge, self-efficacy and illness perception will impact selfmanagement behaviors and physical activity [26-28]. In this study, multimedia training improved the support of friends and so improved patients' perception of social support of friends in physical activity that subsequently resulted to self-efficacy and physical activity promotion. In studies where training has been conducted in the presence of friends of patients, similar findings were obtained $[20,23,29]$ which confirm findings of this study.

In this study, multimedia education could change people's perception of the benefits of physical activity that is consistent with multiple studies' findings with different training methods $[23,24,29]$ which represents the variability of this construct and easiness of its change, therefore, with low-cost and convenient training methods can also increase people understanding of the benefits of physical activity and there is no need for timeconsuming and costly immediate intervention.

People's perception of health and disease affects self-management behaviors [26]. Based on self-regulation model, disease symptoms create cognitive and emotional responses about the disease. The responses pass three stages. At first people respond to threaten or disease symptoms, then change their behavior to overcome these symptoms and finally verify their treatment

Table 1

Demographic characteristics in two groups prior to training.

\begin{tabular}{|c|c|c|c|c|c|c|c|}
\hline \multirow[t]{2}{*}{ Demographic variables } & & \multicolumn{2}{|c|}{ Multimedia group } & \multicolumn{2}{|c|}{ Control group } & \multirow[t]{2}{*}{ Chie square statistics } & \multirow[t]{2}{*}{ P-value } \\
\hline & & $\mathrm{N}$ & $\%$ & $\mathrm{~N}$ & $\%$ & & \\
\hline \multirow[t]{2}{*}{ Gender } & Female & 15 & 37.5 & 17 & 47.2 & 0.735 & 0.266 \\
\hline & Male & 25 & 62.5 & 19 & 52.8 & & \\
\hline \multirow[t]{2}{*}{ Education level } & Diploma & 22 & 55 & 20 & 55.6 & 0.368 & 0.832 \\
\hline & Academic education & 18 & 45 & 16 & 44.4 & & \\
\hline \multirow[t]{2}{*}{ Married status } & Married & 38 & 95 & 33 & 91.7 & 0.343 & 0.449 \\
\hline & single & 2 & 5 & 3 & 8.3 & & \\
\hline \multirow[t]{3}{*}{ Job } & housekeeper & 8 & 20 & 9 & 25 & 7.759 & 0.256 \\
\hline & Employee & 17 & 42.5 & 9 & 25 & & \\
\hline & pensionary & 15 & 37.5 & 18 & 50 & & \\
\hline \multirow[t]{3}{*}{ Drug type } & Metformin & 9 & 22.5 & 9 & 25 & 4.389 & 0.356 \\
\hline & Insulin & 3 & 7.5 & 5 & 13.9 & & \\
\hline & Combine & 28 & 70 & 22 & 61.6 & & \\
\hline
\end{tabular}


Table 2

Constructs' scores of health promotion model during intervention.

\begin{tabular}{|c|c|c|c|c|}
\hline Constructs & Time & $\begin{array}{l}\text { Multimedia group } \\
\mathrm{M} \pm \mathrm{SD}\end{array}$ & $\begin{array}{l}\text { Control group } \\
\mathrm{M} \pm \mathrm{SD}\end{array}$ & P-value (between group) \\
\hline \multirow[t]{4}{*}{ Perceived health status } & Before education & $36.05 \pm 6.21$ & $35.55 \pm 5.95$ & 0.032 \\
\hline & After education & $39.52 \pm 5.71$ & $36.38 \pm 5.87$ & \\
\hline & 3 months later & $40.27 \pm 4.62$ & $37.00 \pm 6.20$ & \\
\hline & P-value (within group) & $\mathrm{p}<0.001$ & 0.299 & \\
\hline \multirow{4}{*}{ Perceived Self-efficacy } & Before education & $48.17 \pm 22.54$ & $58.80 \pm 22.54$ & 0.001 \\
\hline & After education & $56.56 \pm 16.97$ & $53.65 \pm 20.10$ & \\
\hline & 3 months later & $64.86 \pm 16.88$ & $56.65 \pm 21.33$ & \\
\hline & P-value (within group) & 0.046 & 0.114 & \\
\hline \multirow[t]{4}{*}{ Perceived barrier } & Before education & $2.16 \pm 0.43$ & $1.96 \pm 0.49$ & $\mathrm{p}<0.001$ \\
\hline & After education & $1.71 \pm 0.48$ & $1.94 \pm 0.38$ & \\
\hline & 3 months later & $1.63 \pm 0.32$ & $1.85 \pm 0.36$ & \\
\hline & P-value (within group) & 0.042 & 0.256 & \\
\hline \multirow[t]{4}{*}{ Perceived benefit } & Before education & $3.45 \pm 0.37$ & $3.57 \pm 0.35$ & $\mathrm{p}<0.001$ \\
\hline & After education & $3.75 \pm 0.28$ & $3.45 \pm 0.39$ & \\
\hline & 3 months later & $3.70 \pm 0.20$ & $3.54 \pm 0.31$ & \\
\hline & P-value (within group) & $\mathrm{p}<0.001$ & 0.103 & \\
\hline \multirow[t]{4}{*}{ Friend support } & Before education & $2.43 \pm 1.05$ & $2.78 \pm 1.05$ & $\mathrm{p}<0.001$ \\
\hline & After education & $2.36 \pm 1.20$ & $2.80 \pm 0.97$ & \\
\hline & 3 months later & $2.38 \pm 1.08$ & $2.82 \pm 1.02$ & \\
\hline & P-value (within group) & $\mathrm{p}<0.001$ & 0.960 & \\
\hline \multirow[t]{4}{*}{ Family support } & Before education & $2.86 \pm 0.85$ & $3.30 \pm 0.82$ & 0.052 \\
\hline & After education & $3.08 \pm 0.68$ & $3.24 \pm 0.69$ & \\
\hline & 3 months later & $3.12 \pm 0.74$ & $3.28 \pm 0.76$ & \\
\hline & P-value (within group) & 0.044 & 0.831 & \\
\hline
\end{tabular}

Table 3

Mean metabolic equivalent of task (MET) in two groups During Intervention.

\begin{tabular}{llll}
\hline Group & Before education & 3 months later & P-value \\
\hline Control group & $2546.98 \pm 479.48$ & $2500.55 \pm 423.08$ & 0.051 \\
Multimedia group & $2539.81 \pm 532.31$ & $2614.03 \pm 592.45$ & 0.001 \\
\hline
\end{tabular}

effectiveness. The perceived self-efficacy effect control beliefs and can lead to a better understanding of their health statue $[30,31]$. Therefore, in this study since training had been able to improve self-efficacy so had changed people's perception of health status as well.

This study showed that change of perceived health status, selfefficacy, benefits and barrier of physical activity, and friend support could significantly increase the average MET in multimedia group. Results of several studies that have used health promotion model in designing educational program, showed impact of the program on physical activity promotion $[23,24,29]$ in addition, it was effective in a number of multimedia training studies, regardless of the theoretical framework to increase physical activity [12,13,21]. All of these studies verified the findings of recent study, however, since in this study, using the theoretical framework has changed people's beliefs so we should expect that this behavior change has more durability and lasting that its confirmation requires further studies. Therefore, multimedia education based on health promotion model can be a proper approach to improve patients believes about physical activity and promoting diabetes physical activity.

\section{Conclusion}

According to the results seem that planning of education based on the HPM and its implementation by using multimedia has a positive impact on changing health beliefs and therefore creation and promotion of physical activity so it is recommended to use multimedia as an affordable tool to change health beliefs and behaviors of diabetics' health promotion in wide range.

\section{Authors' contribution}

Azita Noroozi contributed to the critical revision of the manuscript, as well as the final approval of the study. Rahim Tahmasebi contributed to the study design, data analysis, and auditing and drafting of the article. Also, Hamideh Lari contributed to the provision and collection of the data.

\section{Conflict of interest}

There is no conflict of interest to be declared regarding the manuscript.

\section{Implication for health policy makers/practice/research/medical education}

Determine the effect of education based on HPM using multimedia on physical activity in type II diabetic patients as an affordable tool to change health beliefs and physical activity of diabetic patients in wide range.

\section{Acknowledgments}

We gratefully acknowledge all persons who helped in this research. This study was supported by the research deputy of Bushehr University of Medical Sciences.

\section{References}

[1] Ayele K, Tesfa B, Abebe L, Tilahun T, Girma E. Self care behavior among patients with diabetes in Harari, Eastern Ethiopia: the health belief model perspective. PLoS One 2012;7(4):e35515.

[2] Mohebi S, Parham M, Pour EM, Kamran A. Self-care assessment in patients with diabetes in qom city in 2013. Arch Hyg Sci 20153(4).

[3] Javanbakht M, Baradaran HR, Mashayekhi A, Haghdoost AA, Khamseh ME, Kharazmi E, et al. Cost-of-illness analysis of type 2 diabetes mellitus in Iran. PLoS One 2011;6(10):e26864.

[4] Naghibi SA, Asghari M, Rostami F. Investigation the effect of education on selfcare promotion in type 2 diabetic patients in noor health centers in 2015. J Health Res Commun 2015;1(2):22-8.

[5] Rocchiccioli JT, O’Donoghue CR. Diabetes mellitus: toward a federal policy. Policy Polit Nurs Pract 2004;5(4):237-42. 
[6] Kirkcaldy BD, Shephard RJ, Siefen RG. The relationship between physical activity and self-image and problem behaviour among adolescents. Soc Psychiatry Psychiatr Epidemiol 2002;37(11):544-50.

[7] Annesi JJ, Westcott WL, Faigenbaum AD, Unruh JL. Effects of a 12-week physical activity protocol delivered by YMCA after-school counselors (Youth Fit for Life) on fitness and self-efficacy changes in 5-12-year-old boys and girls. Res Q Exerc Sport 2005;76(4):468-76.

[8] Global recommendations on physical activity for health. Available from: http://www.who.int/dietphysicalactivity/facts heet_recommendations/en/ index.html.

[9] Heydari H, Baharvand F, Mohebi S, Pournia Y, Tabaraie Y, Kamran A. Predictive power of the trans-theoretical model of physical activity in patients with type2 diabetes. Bull Env Pharmacol Life Sci 2014;3(3):141-51.

[10] Baghianimoghadam M, Hadavandkhani M, Mohammadi M, Fallahzade $H$, Baghianimoghadam B. Current education versus peer-education on walking in type 2 diabetic patients based on Health Belief Model: a randomized control trial study. Rom J Intern Med 2012;50(2):165-72.

[11] N.J. Pender, C.L. Murdaugh, M.A. Parsons, Health promotion in nursing practice. 2006

[12] Khan MA, Shah S, Grudzien A, Onyejekwe N, Banskota P, Karim S, et al. A diabetes education multimedia program in the waiting room setting. Diabetes Therapy 2011;2(3):178-88.

[13] Bell AM, Fonda SJ, Walker MS, Schmidt V, Vigersky RA. Mobile phone-based video messages for diabetes self-care support. J Diabetes Sci Technol 2012;6 (2):310-9.

[14] Zolfaghari M, Mousavifar SA, Pedram S, Haghani H. The impact of nurse short message services and telephone follow-ups on diabetic adherence: which one is more effective? J Clin Nurs 2012;21(13-14):1922-31.

[15] Montazeri A, Vahdaninia M, Mousavi SJ, Omidvari S. The Iranian version of 12 item Short Form Health Survey (SF-12): factor structure, internal consistency and construct validity. BMC Public Health 2009;9(1):1.

[16] Sechrist KR, Walker SN, Pender NJ. Development and psychometric evaluation of the exercise benefits/barriers scale. Res Nurs Health 1987;10(6):357-65.

[17] Noroozi A, Ghofranipour F, Heydarnia AR, Nabipour I, Amin Shokravi F. Validity and reliability of the social support scale for exercise behavior in diabetic women. Asia Pac J Public Health 2011;23(5):730-41.

[18] Noroozi A, Ghofranipour F, Heydarnia AR, Nabipour I, Tahmasebi R, Tavafian SS. The Iranian version of the exercise self-efficacy scale (ESES) factor structure internal consistency and construct validity. Health Educ J 2011;70(1):21-31.
[19] Sallis Jf, Haskell Wl, Wood Pd, Fortmann Sp, Rogers T, Blair Sn, et al. Physical activity assessment methodology In the five-city project. Am J Epidemiol 1985;121(1):91-106.

[20] Chung SK. Effects Of Interactive Multimedia For The Prevention Of Obesity On Self-Efficacy, Beliefs About Physical Activity, And Social Influence. Southern California: Southern California; 2004.

[21] Goran MI, Reynolds K. Interactive multimedia for promoting physical activity (IMPACT) in children. Obes Res. 2005;13(4):762-71.

[22] Wang L-W, Ou S-H, Tsai C-S, Chang Y-C, Kao C-W. Multimedia exercise training program improves distance walked, heart rate recovery, and self-efficacy in cardiac surgery patients. J Cardiovasc Nurs 2016;31(4):343-9.

[23] Mahdizadeh MS, Peymam N, Taghipour A, Esmaily H, Mahdizadeh SM. Effect of health education program on promoting physical activity among diabetic women in Mashhad, Iran: applying social cognitive theory. J Res Health Sci 2013;13(1):90-7.

[24] Noroozi A, Tahmasebi R, Ghofranipour F. Effect of health promotion model (HPM) based education on physical activity in diabetic women. Iran J Endocrinol Metab 2011;13(4):361-7.

[25] Baghiani Moghadam M, Taheri G, Fallah Zadeh H, Parsa M. The effect of instructional designed SMS based on Health Belief Model (HBM) on adoption of self-care behavior of patients with type II diabetes. Modern Care J 2014;11 (1):10-8.

[26] Tahmasebi R, Noroozi A, Tavafian SS. Determinants of self-Management among diabetic patients: a path analysis. Asia-Pacific J Public Health 2015;27 (2):524-34.

[27] Xu Y, Toobert D, Savage C, Pan W, Whitmer K. Factors influencing diabetes selfmanagement in Chinese people with type 2 diabetes. Res Nurs Health 2008;31:613-25.

[28] Bandura A. Self-efficacy: the exercise of control. New York, NY: WH Freeman; 1997.

[29] Fahrenwald NL, Atwood JR, Walker SN, Johnson DR, Berg K. A randomized pilot test of Moms on the Move: a physical activity intervention for WIC mothers. Ann Behav Med 2004;27(2):82-90.

[30] Edgar KA, Skinner TC. Illness representations and coping as predictors of emotional well-being in adolescents with type 1 diabetes. J Pediatr Psychol 2003;28:485-93.

[31] Griva K, Myers L, Newman S. Illness perceptions and self efficacy beliefs in adolescents and young adults with insulin dependent diabetes mellitus. Psychol Health 2000;15:733-50. 